Leka, S., Jain, A., Zwetsloot, G., Andreou, N., \& Hollis, D. (2016). Future challenges of occupational health and safety policy making in the UK. Policy and Practice in Health and Safety, 14(1), 65-80. http://dx.doi.org/10.1080/14773996.2016.1231871

\title{
Future challenges of occupational safety and health policy-making in the UK
}

\author{
Stavroula Leka a, Aditya Jain b, Gerard Zwetsloot a, Nicholas Andreou a \& David Hollis a \\ ${ }^{a}$ Centre for Organizational Health \& Development, University of Nottingham, Level B, Yang \\ Fujia Building, Jubilee Campus, Wollaton Road, Nottingham NG8 1BB, UK \\ ${ }^{\mathrm{b}}$ Management Division, Nottingham University Business School, Jubilee Campus, Wollaton \\ Road, Nottingham NG8 1BB, UK
}

Received 23 May 2016, Accepted 03 Aug 2016, Published online: 12 Oct 2016

\begin{abstract}
Understanding the changing landscape of $\mathrm{OSH}$ regulation and standards and its implications are of central importance for ensuring that OSH outcomes are not compromised and the needs of different types of organisations are met. It is also important for developing appropriate strategies to anticipate and deal with future challenges for $\mathrm{OSH}$ policy making. This paper draws on findings from two qualitative studies with key OSH stakeholders in the UK that were conducted as part of a research programme funded the Institution of Occupational Safety \& Health. The aim of the first study was to elicit the views of key stakeholders on changes in the current OSH landscape so as to understand the nature and implications of these changes. The second study explored stakeholder perspectives on how to secure the optimal OSH landscape in the UK by addressing key future challenges for OSH policy making.
\end{abstract}

Keywords: Occupational health and safety policy making, regulation, stakeholders

\section{Introduction}

Occupational safety and health (OSH) policy making and regulation is not a new societal concern (1). Originating from the law of King Henry (1068-1135), masters were responsible and liable for servants injury or loss of life due to negligence (2). In the nineteenth century, the industrial revolution changed the way the English workforce worked. Factories and mills emerged in swaths across the midlands and northern England, bringing with them dangerous working conditions. People shifted from working in 
small family sized business, often in homes, to working in large factories carrying out larger-scale activities. Mechanisation and the increasing size of industry, meant workplace conditions became more crowded and complex. The employers' knowledge of the workplace diminished as they were no longer able to oversee all elements of the working environment. Furthermore, the interface between machine and man was not common. All these factors combined led to common industrial accidents (1) with young children working extremely long hours in hazardous conditions. During this period, regulation of working conditions was lacking.

These changes first brought questions of occupational health and safety before Parliament and the law courts (3). The industrial revolution had instilled a culture of profit orientation (4), and one could argue the industrial revolution was greatly aided and abetted by the absence of $\mathrm{OSH}$ legislation as fast expansion required low overheads in order for employers to be competitive (5). Parliament intervened, with the only route they perceived viable: legislation. As it will be discussed in this paper, this early landscape evolved in several ways as the world - and the world of work - changed. As a result different approaches were implemented to advance OSH standards, underpinned by different perspectives from diverse stakeholders.

Understanding the changing landscape of $\mathrm{OSH}$ regulation and standards and its implications are of central importance for ensuring that OSH outcomes are not compromised and the needs of different types of organisations, and especially of small and medium-sized enterprises (SMEs), are met. It is also important for developing appropriate strategies to anticipate and deal with future challenges for OSH policy making. This paper will draw on findings from two qualitative studies with key OSH stakeholders in the UK that were conducted as part of a research programme funded the Institution of Occupational Safety \& Health. The aim of the first study was to elicit the views of key stakeholders on changes in the current $\mathrm{OSH}$ landscape so as to understand the nature and implications of these changes. The second study explored stakeholder perspectives on how to secure the optimal OSH landscape in the UK by addressing key future challenges for $\mathrm{OSH}$ policy making.

\section{OSH policy making}

$\mathrm{OSH}$ regulation nowadays does not exclusively refer to legislation. It is seen by many authors as relevant to different types of policies and initiatives - all aiming to regulate health and safety standards in different ways. A more appropriate term to include these various approaches would be policy. Policy 
instruments have typically been differentiated using the 'hard' and 'soft' dichotomy however the definitions for these categories vary greatly throughout the literature (6). Hard law is generally defined as a policy relying primarily on the authority and power of the state in the construction, operation, and implementation, including enforcement, of arrangements at international, national or sub-national level (6). Hard law, based on the concept of legalization, is used to refer to legally binding obligations that are precise and that delegate authority for interpreting and implementing the law (7). Statutes or legislations in developed national legal systems are typical elements of hard law.

Contrasting to this, soft law refers to policies that rely primarily on participation and resource of nongovernmental actors in the construction, operation and implementation of a regulatory arrangement (7). There is a voluntary participation in the construction, operation and continuation of the initiative and a strong reliance on consensus-based decision making. In these instances, a participant is free to adhere to the regime or not, without invoking the sanctioning power of a state (8). Both state and non-state actors can achieve many goals through soft law. In many cases such an approach may be preferable. Soft law provides a basis for efficient international 'contracts' and it helps create normative 'covenants ' and discourses that can reshape international politics (7). These policy instruments range from treaties, to non-binding or voluntary resolutions, and codes of conduct, to statements prepared by individuals in a non-governmental capacity, but which lay down international principles. They also include voluntary standards designed and adopted by businesses and civil society to guide their shared understanding $(6,9)$.

Hard law and soft law each have their advantages and disadvantages. Hard law offers the legitimacy, guaranteed resources and strong enforcement mechanisms that soft law often lacks. Governments acting alone can produce high standards with clear and durable solutions. In contrast, where there is a broader array of stakeholders and interests, as in the UK, soft law arrangements can deliver less stringent standards (6). Soft law offers advantages in that initiatives can be brought about when governments are stalemated. These benefits are particularly important at a time when the demands of intensifying globalisation may outstrip the capacity of national governments to respond (6). However, a disadvantage to such an approach is the compromise that may be required to satisfy all stakeholders in the process (9). An over use of soft law initiatives can lead to uncertainty as competing standards struggle for dominance, and as actors remain unclear about the costs of compliance or its absence, 
and about when governments might intervene to impose a potentially different mandatory regime. These various modes of operation have been used throughout the history of $\mathrm{OSH}$, in the UK and elsewhere (10).

From the 1972 Robens report onwards, the UK OSH arena has witnessed a step-change away from a purely legislative approach towards shifting responsibility to employers and other parties. The political climate (e.g. better regulation and resource constraints), the impact of austerity (e.g. measures taken as a result of recessions), major industrial accidents (e.g. Flixborough) and the emergence of various new risks (e.g. psychosocial risks) have elevated the importance of OSH among enterprises and their stakeholders and thus have significantly impacted on the actions taken by these parties (10).

In addition, it is clear that there is a mix of what could be deemed 'traditional' stakeholders (e.g. government agencies, trade unions, employer organisations) and 'new' stakeholders (e.g. insurers, professional associations, standardisation bodies) who are active in the $\mathrm{OSH}$ arena, highlighting the breadth of stakeholders and the multiplicity of their interests. The national OSH landscape in the UK (11) includes a multitude of stakeholders: employers and their representative bodies; the self-employed; workers and their representative bodies; Government, through its departments and agencies (Health and Safety Executive, local authorities etc.); professional bodies; voluntary and third sector organisations (12). There is a complex network of sources of health and safety support, advice and information available to both employers and workers which are largely outside the direct control of either the HSE or local authorities which together form the national OSH landscape in the UK (11).

Furthermore, $\mathrm{OSH}$ has taken on political significance and has been subject to a deregulatory agenda for several years $(13,14)$. As such changes have often been enacted without strong evidence, and processed in an opaque manner (for example attempting to enact reforms without consultation (10). Macro level factors have affected the actors within the OSH landscape, and as such the stakeholders and their ability to influence OSH standards have constantly been changing (15). In addition, there has been an associated shift in $\mathrm{OSH}$ risk perception (as well as sensitivity and tolerability) - within the broader context of what has been called a post-trust society (16), in which, as a consequence of trust failures, relatively minor mistakes may jeopardise the social acceptability of specific (such as OSH) risks. As a result, the legitimacy of $\mathrm{OSH}$ has been debated over the years and, relevant to this, so has that of $\mathrm{OSH}$ professionals. 
Taking this complexity into account, to bring about improvements in health and safety standards, there is a need to reflect on the OSH landscape, lessons learned over the years and avenues to focus key stakeholders in working together towards achieving a set of common goals. Thus this research aimed to explore: stakeholder perspectives on recent changes in the OSH landscape in the UK, following the two major reviews of Young (17) and Löfstedt (18) and subsequent reforms; and their views with regards to future challenges in OSH policy making in the UK.

\section{Method}

This study included two stages: the first involved forty semi-structured interviews with key OSH stakeholders that were identified on the basis of a stakeholder map developed as part of this research; the second included two stakeholder focus groups. The study was approved by the University of Nottingham, Faculty of Medicine \& Health Sciences Research Ethics Committee. Participation in each study was entirely voluntary with participants free to withdraw from the study at any time without giving a reason. The identity of the participants and the information they provided was kept anonymous and treated in confidence to comply with UK Data Protection Laws.

The aim of stage 1 interviews was to elicit the views of key stakeholders on changes in the current OSH landscape so as to understand the nature and implications of these changes. The interview schedule was informed by a policy analysis and literature review conducted in this research and the findings of a series of OSH case study analyses (see 10). The items were developed by the members of the research team and the interview schedule was cross-checked and agreed by the project Advisory Board, representing key stakeholders and experts. The questions focussed on understanding what stakeholders perceived as the biggest changes in $\mathrm{OSH}$ and the opportunities and constraints presented by these. Stakeholders were also asked to consider whether these changes would affect the role of their organisation, as well as the implications for OSH outcomes, and for SMEs and practitioners. The final area of interest focussed on the future of OSH policy, including recommendations and key areas which required balance. 
Thematic analysis was conducted where the transcript of each interview was entered into NVivo 10 and an initial coding was conducted, establishing many specific preliminary themes. These were discussed with the research team and grouped together to form higher order themes arranged in a thematic framework. To ensure inter-rater reliability, all four members of the research team reviewed the collected emergent themes, and the coded data.

The stage 2 focus groups explored stakeholder perspectives on how to secure the optimal OSH landscape in the future. Stakeholders identified as key actors in the OSH arena participated in the two focus groups. To be able to effectively facilitate discussion and accurately reproduce the discussion for analysis, participants were limited to approximately 10 stakeholders per focus group (18 in total). A list of stakeholder groups represented, and number of participants attending ${ }^{1}$ is presented in Table 1.

INSERT TABLE 1 HERE

The schedule of the two focus groups was identical. First, the facilitator introduced the topic area and briefed participants on the research project, as well as key findings thus far. The facilitator then invited discussion on four key topics focusing on $\mathrm{OSH}$ legitimacy, $\mathrm{OSH}$ regulation, health in $\mathrm{OSH}$, and $\mathrm{OSH}$ practice.

Data was analysed using framework analysis following the key stages reported by Krueger (19) and Ritchie and Spencer (20). The analytical framework was informed by the previous stages of the research. Data was examined to evaluate the extent to which it fit key themes identified in the previous stages of the research, indicating a very good fit. Hence data from the current stage of the research which fit under those themes was coded as such. This further validated many of the prior emergent themes. Several new themes emerged using the analysis process described by Braun and Clarke (21). Relevant extracts were collated and grouped into emergent themes. The data was then re-assessed

\footnotetext{
${ }^{1}$ For example: the Health \& Safety Executive, the Health and Safety Laboratory, the Office for Rail Regulation, Local Authorities, IOSH, the Chartered Institute of Environmental Health, British Ceramics Confederation, and the University Health and Safety Association.
} 
refining the emerging themes. The final thematic framework was then assessed by all members of the research team to ensure the validity of the themes (see Table 2).

\section{Results}

Five main themes including twelve sub-themes emerged from the analysis and are presented in Table 2.

INSERT TABLE 1 HERE

\section{Reiterating OSH legitimacy}

The first theme on reiterating OSH legitimacy centred the perception of OSH by policy makers and the public, including the role of the media in shaping these perceptions, and the perception of risk.

\section{Perception of $\mathrm{OSH}$}

In particular, a view was expressed that $\mathrm{OSH}$ policy has developed a reputation for being excessive, and being seen to tackle the issue is likely to garner public support. As such, $\mathrm{OSH}$ reforms could be understood as an attempt to alter the public perception of $\mathrm{OSH}$ rather than any legitimate issues with the system. A representative from an employer's association supported such a notion: "a lot of reforms [...] it's not about improving health and safety performance, reducing the number of injuries in the workplace or work-related ill health. Actually it's about improving the public perception of health and safety".

However, some respondents felt that with the increased publicity around $\mathrm{OSH}$, this presented the industry with an opportunity to be proactive in voicing its success stories and historic achievements. As one insurer noted "I am reminded to think about Monty Python and what the Romans do for us and what did Health and Safety do for us? And it took us from the Industrial Revolution to where we are now. And so if we are looking at how many lives were saved progressively, as new acts, new regulations came along etc. Even if you only go back to the Second World War, there must be a fairly significant reduction in the number of fatalities per year, but we don't celebrate that". 


\section{Perception of $\mathrm{OSH}$ risk}

Linked to this perception, a common view espoused by research participants was that there remains uncertainty around what $\mathrm{OSH}$ risk is, and more specifically how it differs from OSH hazard. For example, as one government agency stakeholder noted, this confusion around the two terms is apparent both within some HSE circles and industry: "I don't think hazards and risks have been well understood anyway. I say that from within HSE as well, because often the two terms are used interchangeably and they have been over for many, many years. And l've worked in industry as well, and seen the same misconceptions there".

Another issue is how society perceives OSH risk compared to other types of risk. For example, one government agency representative noted how there is a general ignorance amongst the general public around $\mathrm{OSH}$ risks compared to environmental risks: "But there's an issue about society societal perception of risk isn't there, in terms of environment versus health and safety. The public at large, get more information about...environmental issues [that] might affect them than maybe about health and safety ones".

A common view was that when thinking of risk it is important to take into consideration whether the risk is perceived to be relevant to the macro (i.e. international/national) level or to a more micro level (i.e. industry/workplace). This point was succinctly captured by one government agency representative: "What is acceptable risk? And that's very much context dependent, say if you are looking at the national level, obviously you're are taking in high hazard industries as well as what are considered low hazard, or low risk".

All participants agreed that further education is needed in relation to $\mathrm{OSH}$ and associated risks with one employer representative noting that education could begin as early as school. However currently the wrong messages were being sent: "you could do OSH type training in school so that people take it seriously and say this is not rubbish, this is about not being killed or injured or getting a disease"'.

Prioritising health and well-being in $\mathrm{OSH}$ 
As highlighted above, the health aspect of $\mathrm{OSH}$ is a key priority in the modern workplace but also challenging to tackle. This is because of a historical focus of $\mathrm{OSH}$ on predominantly safety issues, measurement difficulties, increasing complexity between health and well-being and associated financial costs.

Health in $\mathrm{OSH}$

Most participants felt that $\mathrm{OSH}$ had predominantly focused on safety issues, to the detriment of healthrelated issues. For example, an insurance association representative noted: "there needs to be great concentration on the prevention of ill health. I think that's one of the areas in this country that we've not really dealt with properly". This perspective was shared by an academic: "one particular area where OSH has failed to do this, is in relation to the 'H' bit, the health bit. [...] the TUC, has quite a lot to say about this. And they say that OSH is obsessed at reducing the risk of injury but they're doing it at the expense of occupational health. [...] I would echo that. I would say they've also done it at the expense of public health".

The stakeholders agreed that there is a need to engage on occupational health and noted that the recent reviews had not considered this aspect adequately. As one union representative noted: "we seem to be taking a backwards step at the moment. And that's reflected in a lot of the government's approach. I mean you look at the Young report. There is very little about health and ill health". Similarly, looking forward, stakeholders felt that the landscape for those involved in occupational health would be challenging. For example, a second union member mentioned: "there is a lot of changes that are kind of increasing the gap between safety and health. I'm thinking here of the changes around RIDDOR, the reduced emphasis on health. It could be quite difficult for occupational health people to maintain their [...] jobs actually".

With regards to the wellbeing/occupational health distinction, some participants aired caution around using the two terms interchangeably. As an OSH practitioner pointed out: "I think we have to be careful, particularly this Wellbeing Agenda getting mixed up with what should be the health aspect of Health and Safety". However, a stakeholder from a trade association was of the view that the synergies between occupational health and well-being could be used to work in favour of the former: "the problem 
with the wellbeing agenda ... no one has direct ownership. And I think there is a definite, an opportunity for Health and Safety to align with that, which will take the Health agenda with it".

Another emerging issue was around the shift most participants had witnessed whereby organisations were increasingly framing the responsibility for occupational health upon their employees rather than taking ownership. In the following quote an $\mathrm{OSH}$ practitioner notes how the use of wellbeing terminology actually facilitates this attitude: "you have got these new companies setting up about "you need to have your workforce resilient". What does that mean? So it's the individual's fault that they are getting ill. And it's couching this Wellbeing Agenda, rather than what occupational health should be looking at is what is... What is that individual, those employees doing there, in that workforce? Is there something there that's making them ill? If there is, we need to know about it".

Respondents did however note that occupational health has not been completely ignored, with many attendees highlighting the contribution of the 2008 report 'Working for a healthier tomorrow'. However, the extent to which the recommendations from the report have been enacted was raised by respondents as a cause for concern. A government agency representative pinpointed why the recommendations from 'Working for a healthier tomorrow' had not been enacted: 'there's a complete disconnect between what DWP are trying to achieve in terms of health related to the original Carol Black report, and what the Health Service can actually deliver". Who bears responsibility for paying for the costs associated with ill health at work was a key discussion point - the onus at present is largely on the state and individuals - not employers.

Genuine evidence-based policy making

A second theme related to the need for genuine evidence-based policy making in $\mathrm{OSH}$. Here, several issues were raised by the research participants including the need for a multi-policy proportionate approach after consultation with key stakeholders, based on long-term thinking rather than short-term interests, while being aware of economic and political influences and issues surrounding the use of data and considering the impact of policy actions.

\section{Political and economic influences}


Participants highlighted extensively challenges in relation to economic and political influences on OSH. Perhaps the most commonly mentioned macro factor was the economic climate and the impact that this has on $\mathrm{OSH}$ standards. A standardisation and certification body interviewee suggested that a shortage of resources would negatively affect people's decision making in relation to OSH issues: "The austerity [...] and the effect on people working and how they will work and what jobs they will take on, and how they will do them". A trade association interviewee added: "there is an impact in terms of the economy [...]. In terms of the expenditure people are willing to put into safety equipment, and activities in this area. And there's a downgrading to some extent of the quality of equipment". Several stakeholders also mentioned issues related to resources, and in particular financial limitations, which inhibited stakeholders' ability to pursue desired goals and objectives

A second factor for most was the political nature of regulation. As one employers' association participant described: "There's an ideological movement against regulation and health and safety is one area that is getting it in the neck". Linked to this were issues raised with the OSH system and whether OSH reforms were a legitimate requirement. According to a government agency stakeholder, "all the industries that I have had dealings with, those who were sort of thinking ahead, didn't see occupational safety and health as a monster. They actually saw it as a benefit to their business". Likewise, the general public was thought by most participants to see $\mathrm{OSH}$ as legitimate, a view succinctly summarised by one professional association attendee: "We still live in a society where l'd hope that you spoke to $99.9 \%$ of the population and asked them if they want to work in a workplace that is healthy and safe, they would say 'Yes'". Several participants also commented on the process by which reform was taking place, particularly on the decision for deregulation in the face of the claim that OSH was burdensome.

Several regulatory initiatives were reported to be at their origins driven by the requirements of the European Commission and future revisions of existing European legislation would have an effect on national OSH legislation. As one trade union attendee noted, the EU regulatory framework differs from the UK framework (which in principle is risk based): "When you get in Europe, the big complaint about European directives is that they are hazard based, and not risk based. That's the general criticism". Although there were mixed views on the level and benefit of EU regulation, as an insurance organisation interviewee reported, they were unaware of any organisation to report OSH as being burdensome: "We have never had it put to us that it is a burden, and even when we expressly asked about it". 


\section{Multi-policy proportionate approach}

The subject of policy is of course a complex issue and there is no one size fits all approach. Testifying to this, a government agency representative noted that which type of policy was the appropriate driver for action in $\mathrm{OSH}$, including legislation, was highly context specific: "it depends on the level of maturity of industry you're talking about and the level of risks associated with that industry. So I think in areas of low maturity and high risks, actually regulation is very important to provide the framework for appropriate use of controls, systems, leadership etc. to manage OSH issues. So I think at that end regulation is important. I think at the low risk, mature end, it's probably less important because they're more about culture, continuous learning, improvement etc".

As such participants discussed the need of having a combination of policy initiatives to regulate OSH in the future (both hard and soft law) after consultation with key stakeholders to achieve optimum results. As an OSH practitioner noted: "I think having a balance of regulation, and I mean, there's a place for financial incentives but it depends what the context is really. [...] But I think it would be good to have some sort of incentivising around trying to improve standards but it's a difficult topic".

\section{Long term, independent thinking}

All participants agreed that long term, independent thinking needs to be adopted. To achieve this, it is important to adopt thinking that is independent from political ideology and is orientated towards long term benefits rather than short term considerations. Several stakeholders noted that previous and ongoing $\mathrm{OSH}$ policy decisions were affected by short term thinking, which had been particularly detrimental to $\mathrm{OSH}$. For example, one interviewee from a professional association noted: "I would suggest you could see as a fault in government policy, that it looks short term. Therefore the accident and safety statistics tend to drive it, rather than the consideration of the longer term impacts such as the costs to, if you like, the country, of chronic diseases, of stress, of musculoskeletal issues. [...]. There is very much, it seems to me, a short term focus to get us out of the mess, rather than a long term consideration of what are the burdens over a longer term. Because governments are only there for say five years. And they tend to focus on short term rather than longer term issues". 
Other suggestions included the creation of an independent body to assess major issues in UK policy, independent from government influence, as one stakeholder representing insurance associations noted: "Our suggestion is that we need some intelligent thinking going on and there is a lot of stuff there in academia and in industry that wants bringing together [...]. We may need to say as a country competing in the future 'how do we manage?', and you can't do that via the political process [...] but if we had an independent risk commission of authority people [...] that's the sort of body that could look at it and perhaps come up with something sensible".

\section{Measurement}

The use of evidence was also extensively debated with participants highlighting that a major challenge in terms of policy initiatives is measuring their impact and effectiveness; particularly when trying to evidence causation at the practice level. Similarly, attributing success outcomes directly to an initiative is not a straightforward task. Measurement of effects on occupational health in particular is troublesome, with the views on tangibility and latency being recognised by the participants. As they argued, longterm measurement is required: "I don't think we can fully appreciate the impact (of the regulations) because of the latency of the diseases involved" (government agency representative). The issue of scalability when attempting to measure a policy initiative's impact was also raised as a challenge: "we have quite a lot of local success, i.e. at the organisational level, but when you're dealing with national data, it doesn't always come through; it gets lost" (OSH practitioner).

Promoting leadership and business engagement in $\mathrm{OSH}$

Another theme was, not surprisingly, related to engaging businesses in $\mathrm{OSH}$ with the role of practitioners highlighted as crucially relevant, as well as educating business leaders.

\section{Engaging business}

Much discussion surrounded how best to drive OSH in business. Leadership has long been identified as material in the process of creating a safe and healthy workplace. Stakeholders reiterated that need for the future as well. For example, a certification and standardisation body interviewee noted: "one of the biggest issues, is to make sure that managers have to take the lead and be seen to be taking the lead, and this is very much in the way that the new standards are being written". An insurance 
interviewee took the commitment one step further, suggesting that the board should be involved in $\mathrm{OSH}$, not just managers: "we always emphasise it should become a board room issue. It's not an issue to say it's someone else's responsibility".

As one government agency attendee noted, the optimal approach would be for $\mathrm{OSH}$ to be thought of as a key component within business management rather than an adjacent element: "the quality of health and safety management, I think it is actually a marker of quality of management. And where it works well is when it is integrated into the whole management process, and is not seen as an add on".

One of the most discussed issues under this theme was understanding which policies organisations would best respond to, as a precursor to how best to devise policy in the future. All participants felt that legal requirements were necessary as made clear by one stakeholder representing a trade association: "history repeats itself that sectors left to themselves, people don't do what they're meant to do. Poor ethics, poor morals, and greed and financial gain are the drivers rather than good health and I think that's just another aspect of work. Actually you need good regulation". However, even legislative requirements would not mean that a company would be compliant. One government agency representative noted how legal requirements could effectively be turned into financial cost benefit analyses: "when lawful action was taken against a small firm who had a load of notices and when we went back to check whether he'd done it, he hadn't actually done anything. Basically [they] said 'when you served me with the notices I looked at how much I was going to be fined if I didn't comply with the notices and I looked at how much l'd be fined if I didn't pay my VAT. And I had so much money, I paid the VAT and didn't do the things you wanted me to. You'll take me to court but the fine you'll give me will be less than the fine the VAT man would have given me'. And that's the choice he made, and that's the stark reality for a lot of small firms I suppose".

One employer representative placed particular focus on micro firms: "SMEs covers such a wide range. I think l'd split it between the micro ones, and my concern would be the micro level that people just think health and safety is not an issue that I have to concern myself with, that would be my concern. For the bigger SMEs, when you're getting into the 20 employees and above, my concern is a little less there because I think other factors begin to come into play [...], they have to probably make sure they're doing things right, they find themselves on procurement lists for tier one suppliers for things. So they know 
that they may have to satisfactorily answer questionnaires from other companies who wish to deal with them".

Adopting a responsibility approach was thus seen by some stakeholders as a supplementary approach, with one trade association representative noting that this was a growing pressure: "the other changes [...] are around the sort of moral and ethical social responsibility of companies. Health and safety is aligned within that setting, there will be a growth within possibly business annual statements and an accountability through that, being driven through moral and ethical governance". However, once again, it was recognised that this approach alone would not suffice, and a combination of measures was required. As one OSH practitioner noted: "The reality is that there are business out there which are pretty sort of non-caring organisations, so the reality is that you need some basic core of regulation in the background to make sure that those people are dealt with".

Financial drivers were also discussed as a possible motivator; this was perhaps best captured by one insurance interviewee who noted that when the cost of employers' liability insurance rose, they perceived $\mathrm{OSH}$ to have far higher prominence in organisations because of the financial implications: "When the cost of ELI rocketed, which it did do in the early 2000s, we actually found ourselves dealing with board directors and that had one tremendous advantage, from our point of view it put health and safety on the board room agenda, where it had never really been before [...]. Because it was on the board room agenda, things started to happen because of course the boards can control the flow of money into an organisation and what they prioritise becomes more important".

Indeed the same stakeholder noted that financial incentives can be more salient than legislation: "For an average big company, I don't think it is that concerned about regulatory compliance. I mean that might change with FFI somewhat, but they're more interested in what influences their insurers, because if their premium goes from $£ 400,000$ to $£ 600,000$ that's a big budgetary item. Well a visit from your regulator, if you get one at all, is not going to have that sort of cost implication".

\section{Educating business leaders}

Finally, as many of the issues related to OSH were identified as deficits in knowledge, it was no surprise that many stakeholders spoke of furthering education in $\mathrm{OSH}$. For example in relation to health, it was identified that not only is there a need for increased commitment but increased understanding of 
emerging risks. As argued by one OSH practitioner: "people need to understand. It's all around worklife balance, but what's happened with that process is employers have focused on the route: 'Ok we'll provide gym membership' [...]. They're not looking at it as a whole [...] the issue of stress, it is holistic. It is about the individual and how resilient they can be and what they do and how they work. But they need to be taught about this [...] so there is an awful lot of educational work that needs to be done in that area, definitely".

Other stakeholders mentioned that a lack of OSH awareness was linked to a general deficit in the knowledge that organisations, particularly SMEs, had access to. As one employer association interviewee noted: "there needs to be a much bigger education program, and I don't mean around risk as a concept, but a much bigger education program which help small business know and understand where they can go to get advice".

\section{The OSH 'industry'}

An interesting view which emerged among stakeholders was that $\mathrm{OSH}$ had become an industry. As one government agency attendee noted: "Unfortunately with health and safety, we have turned it into an industry". This view was also shared by a OSH practitioner who noted how the field had become more commercialised: "I used to go to Health and Safety Expo, it is big business, it has just become a business environment".

A key issue was the role of practitioners within the $\mathrm{OSH}$ arena and whether or not they were part of the 'problem'. A consensus appeared to emerge that this depended, to a large extent, on their level of competence. Many comments were made about the need for practitioners to develop broader perspectives. One representative from a professional association commented on the soft skills required: "leadership skills and communication skills. If you're going to get the senior management within an organisation to manage risk as they should be doing, they may well need somebody to lead them, actually point them in the right direction, and influence them".

Another representative from government agencies noted that in the context of organisations, several angles need to be considered as one OSH practitioner had told him that: "feedback I got from that [...] was that I reached for legislation far too early in the discussion and I hadn't used the cost-benefit analysis angle, the moral angle. And l'd gone far too quickly for the legal angle". 
Strengthening stakeholder partnership

For many of the goals already mentioned to be achieved, participants highlighted that partnership among key stakeholders would need to be strengthened.

\section{Stakeholder/practitioner autonomy and influence}

Stakeholders highlighted that changes in the $\mathrm{OSH}$ landscape had implications for stakeholder/practitioner autonomy and influence. Government related stakeholders noted that they felt compelled to follow government with its proposed changes. This appeared to affect the HSE particularly negatively as one professional organisation mentioned: "they [HSE] are really struggling and I think politically they're having their strings pulled quite a bit, which really ties their hands on what they can do and what they can provide. And it's a massive shame because it doesn't help anyone".

Other stakeholders also noted knock-on effects of the changes being implemented. For at the individual worker level, one trade union representative argued that there might be some constraints felt on the ability to blow the whistle on OSH issues: "if you create a culture where health and safety is taken less seriously, I think it makes it much harder for people to speak out about health and safety concerns, because they are seen as somebody who is standing in the way of growth and progress so forth. So from that point of view, it can be negative at a local level".

However, some stakeholder groups did not feel that their ability to act was affected due to their independence, as one professional association noted: "We don't have our strings pulled by anyone. So in terms of what we genuinely believe are the right ethical policies, procedures, practices to go down, we will still shape our path down those avenues".

\section{Working in partnership}

Linked to many comments throughout the findings, a key recommendation was the need for partnership work at all levels of OSH stakeholders. One key area was that between regulator and duty holder. Similarly stakeholders were keen to emphasise that within government: "there needs to be much more partnership and understanding between people who work for public health and people who work in OSH [...]. HSE would know about some of these [work-related antecedents to ill-health], but because they're 
not properly linking the sort of health and safety side with the Department of Health side, the health practitioners and the OSH practitioners not necessarily working closely together, there are opportunities being missed" (union interviewee).

The need for closer collaborative working between government and professional associations who represent health and safety professionals was also raised, for example an OSH practitioner stated: "one of the things is... cross-fertilisation of all those trade bodies and groups getting together with the HSE. What we haven't seen is the formal professional bodies fully get together and promote a way forward, a message from RoSPA, IOSH, and the British Safety Council, to stand together and say, 'Well, no, we represent $X$ thousands of members, of professionals and this is what they're saying"'.

\section{Discussion}

This research has highlighted that the OSH landscape is dynamic. As the landscape has evolved over the years in the UK, so have the perceptions and attitudes in relation to $\mathrm{OSH}$ alongside socioeconomic and political developments. The changes in the perceptions and attitudes of OSH stakeholders have had an impact on the legitimacy of $\mathrm{OSH}$ and $\mathrm{OSH}$ professionals. Perhaps two of the most apparent observations are a trend towards deregulation of $\mathrm{OSH}$ and an associated shift in $\mathrm{OSH}$ risk perception (as well as sensitivity and tolerability).

Research reveals that trust plays a major role in shaping public views and risk decisions. The issue of trust has come to the fore as it has become apparent that confidence in industry and government is declining in many countries. Löfstedt (22) suggests a number of explanations of why the public's trust toward these bodies has decreased dramatically, including:

- The 'sheer number and size' of regulatory action.

- The rise of 24-hour television and Internet, offering alternative non-expert sources of information.

- The increasing concentration of political power.

- Media amplification. 
The development of OSH legislation in the UK, at least during certain eras, has been criticized as being haphazard and or reactive (23) to specific situations such as major industrial accidents and disasters, often characterised as regulation reflex or knee-jerk regulation, defined as 'neurotic over-regulation in response to overreaction to risks, accidents and incidents' (24). Another issue around regulatory action relates to the enforcement of regulation and the negative impact on stakeholders. Both the 2010 Young review and the 2011 Löfstedt review highlighted the challenges posed by the way legislation is interpreted and applied, and the inconsistent enforcement of OSH regulations and negative influence of third parties such as OSH practitioners/consultants.

The significant role played by the media as a stakeholder in shaping perceptions and attitudes in relation to OSH has also been highlighted. Petts, Horlick-Jones and Murdock (25) examined the media's role in the amplification of risk among the public and found that tabloids tended to personalise risk events and editors had a tendency to move the emphasis away from the immediate precipitating causes of risks to their consequences for the individuals and groups they affected. Likewise, Boden (26) found tabloids drew extensively on personal testimony in the construction of stories. According to the author, this approach produces self-reinforcing 'circuits' between lay public representations, everyday experience and social conversation.

However, research findings highlighted that stakeholders were of the view that OSH was perceived as illegitimate and burdensome primarily by government rather than by the general public or industry. This finding was contrary to that reported in Lord Young's (17) report which states that "the standing of health and safety in the eyes of the public has never been lower" (p.5). It is therefore important that efforts are made to address the challenge posed by the perceived illegitimacy of OSH. Academics (e.g., 27,28) have noted how perception within OSH differs widely between experts and the general public. Raising awareness and educating stakeholders and making efforts to streamline legislation (e.g. better regulation initiatives) can therefore help to legitimise $\mathrm{OSH}$ for all stakeholders.

It is, however, important to emphasise that better regulation initiatives should not end up solely as deregulation. When allied to risk-based rationales for enforcement, responsive regulation can allow a deregulatory momentum to develop. But, according to the research participants, it is important that this is applied appropriately and according to the evidence base. To ensure OSH legitimacy does not suffer 
because of political or media interests, there is a need to raise awareness and engage all key stakeholders while being more vocal about OSH successes over the years.

Engaging key stakeholders was highlighted as a key priority. Participants reported that getting involvement and getting into the business was difficult as there was still a lot of scepticism to overcome, particularly from SMEs. It is important therefore to emphasise and reiterate the value of OSH management and practice to promote not only workers' health and safety but also organisational health, increased productivity, enhanced corporate image/reputation and organisational sustainability. To achieve this, OSH management needs to be positioned and recognised as an integral part of business operations rather than as an add-on.

To achieve this, the need for continual training, education and re-education was repeatedly highlighted throughout this research. Training and education programmes should be targeted not only at managers, health and safety representatives and $\mathrm{OSH}$ practitioners but at colleges, universities and business schools. It is important for training and education programmes to clarify the concept of risk and also adequately cover content on new and emerging risks rather than focusing primarily on traditional OSH issues. Linked to this issue, is the clarification of the concept of 'low-risk' and how the classification of sectors, activities, areas, businesses, and industries come to be as such. Risk based regulation often focuses on safety concerns. However, often this rationale ignores the current evidence base and taking into account new and emerging risks in the OSH landscape which represent major concerns in modern workplaces (such as psychosocial risks and health-related concerns, 10). In addition, research participants expressed concern that many small and micro businesses which are now labelled 'low-risk' actually face some of the largest health and safety risks. It is therefore important that further awareness is raised across all stakeholders on the notion and severity of 'risk' to reduce ambiguity and promote good practice according to the evidence base.

The question of balance in OSH policy and practice has been raised repeatedly in this research. Models used in $\mathrm{OSH}$ policy making and $\mathrm{OSH}$ practice are traditionally based on economic considerations which, on their own, are unsuitable to concepts such as safety, and even more so health (and certainly not without moral criticism). Better regulation, often characterised by deregulation, has been a key theme since the 1970s that has expanded at EU level $(4,29,30)$. Stakeholder consultations and impact assessments (IAs) are now increasingly being considered as essential parts of the policy making 
process (31). Although this model attempts to inject greater objectivity and transparency into the regulatory process, and thus legitimise it particularly in the eyes of business and industry (32), there have been a number of criticisms. For example, Hood, Rothstein and Baldwin (33) note that the techniques of better regulation, and specifically IAs, are more appropriate for narrow 'regulatory craft' rather than for policy problems and conceal difficult qualitative trade-offs that have to be made. Issues encountered in regulatory reviews and application of IAs include: poorly defined objectives leading to omissions or parts of the policy structure not covered; inadequate use of evaluation techniques; complexity and fragmentation as a result of which too many checklists can cover a bewildering range of issues and reduce the process into a check box ticking exercise; and finally poor integration with consultation processes which limits their practical effectiveness $(27,34,35)$. Furthermore, not everyone agrees that IAs, particularly cost-benefit analysis, are justified or useful. Such researchers believe that IAs solely focusing on quantification and monetisation is a form of pseudo-science, blinding us to the real values at stake (36).

A preoccupation with occupational safety to the detriment of occupational health was also raised by the majority of respondents within the present research. James, Tombs and Whyte (37) note that the Löfstedt report acknowledges that occupational health conditions can occur in the kinds of workplaces that are traditionally considered less risky, such as offices and the service industry but the report proceeds with no further commentary on the occupational health issues that workers in such premises face. In addition they note that a further problematic feature of defining workplaces as 'low-risk' is that one of the most dangerous OSH problems UK workplaces face, work-related stress, is health-related. Some respondents were also of the view that the emergence of occupational health was linked to the changing nature of work (particularly in light of the current economic climate) with businesses increasingly requiring employees to 'achieve more with less'.

The majority of participants in this research applauded the Black review (38) as a rigorous piece of work and noted the recommendations which emanated from it as laudable. However, respondents were not as optimistic that these recommendations had been acted upon. A consensus appeared to emerge that the government is still predominantly focused on the symptoms of occupational ill-health (i.e. absence management). These assertions appear to be borne out by the government's independent review of 
sickness absence by Black and Frost (39) which builds on the findings of the Black (38) report. There is still a lot that needs to be done to integrate 'health' more concretely in OSH policy initiatives.

This research supported the view that a participatory approach from all stakeholders within the OSH landscape is required in order for several of the facets of the optimal OSH landscape to be achievable. These views were also shared by Harrison (40) who notes that in order for the OSH system to make further gains, there is a need for greater partnership working between the regulator, employers and social partners. Partnership is more important now than ever with the emergence of many nontraditional $\mathrm{OSH}$ stakeholders and the role they can play in regulating $\mathrm{OSH}$.

Working in partnership is particularly important to overcome constraints and learn from each actor's initiatives. To do so, it is necessary to critically review further what actions and approaches might work best and under what conditions. As the OSH regulation landscape in the UK is complex and dynamic, various perspectives on various possible policy options and initiatives need to be explored comparatively to achieve a better understanding and make recommendations on the way forward. This research has already identified some key success indicators and priorities, but it has also highlighted the lack of evaluation in these efforts. Since certain trends have consistently been repeated in the OSH landscape over the years, a great deal of knowledge can come from examining and learning from the past and from sharing the lessons learned. Only then can we move closer to the optimal OSH landscape, by implementing a sustainable process of policy and practice development and evaluation.

Acknowledgments: This project was funded through the Research Programme of the Institution of Occupational Safety \& Health (IOSH) in the UK. 


\section{References}

1. Henshaw JL, Gaffney SH, Madl AK and Paustenbach DJ. The employer's responsibility to maintain a safe and healthful work environment: A historical review of societal expectations and industrial practices. Employee Responsibilities \& Rights Journal 2007; 19 (3): 173-173.

2. Rabinowitz RS. Occupational Safety and Health Law. Washington DC: Bureau of National Affairs, 2002.

3. Barrett B and Howells R. Occupational Health and Safety Law. London: Pitman Publishing, 1997.

4. Dawson D, Willman P, Clinton A and Bamford M. Safety at Work: The limits of self-regulation. Cambridge: Cambridge University Press, 1988.

5. Crombie KF. Deregulation of health and safety laws in the USA and UK: Past practices, recent trends and future options. Corporate Crime \& Governance 2000.

6. Kirton JJ and Trebilcock MJ (Eds.) Hard Choices, Soft Law: Voluntary standards in global trade, environment and social governance. Aldershot: Ashgate Publishing Ltd, 2004.

7. Abbott KW and Snidal D. Hard and soft law in international governance. International Organization 2000; 54 (3): 421-456.

8. Ikenberry J. After Victory: Institutions, strategic restraint and the rebuilding order after major wards. Princeton: Princeton University Press, 2001.

9. Chinkin CM. The challenge of soft law: Development and change in international law. International \& Comparative Law Quarterly 1989; 38: 850-866.

10. Leka S, Jain A, Andreou N, Hollis D and Zwetsloot G. The changing landscape of occupational health and safety regulation in the UK. IOSH: Leicester, 2016.

11. Better Regulation Executive (BRE). Improving Outcomes from Health and Safety: A report to government by the Better Regulation Executive, 2008.

12. Health and Safety Executive (HSE). The Health and Safety of Great Britain - Be part of the solution. HMSO, 2009.

13. Bain P. Human resource malpractice: The deregulation of health and safety at work in the USA and Britain. Industrial Relations Journal 1997; 28 (3): 176-191.

14. Dalton AJP. Safety, Health and Environmental Hazards at the Workplace. London and New York: Cassell, 1998. 
15. Walters DR. Identification and assessment of occupational health and safety strategies in Europe 1989-1994: United Kingdom. Working Paper No. WP/95/63/EN. Dublin: European Foundation for the Improvement of Living and Working Conditions, 1996.

16. Slovic P. Perceived risk, trust, and democracy. Risk Analysis 1993; 13(6): 675-682.

17. Young D. Common Sense, Common Safety. London: Cabinet Office, 2010.

18. Löfstedt RE. Reclaiming health and safety for all: An independent review of health and safety legislation. Department for Work and Pensions. HM Stationary Office, 2011

19. Krueger RA. Focus groups: A practical guide for applied research. Los Angeles: Sage Publications, 1994.

20. Ritchie J and Spencer J. Qualitative data analysis for applied policy research. In A Bryman and RG Burgess (Eds.), Analysing Qualitative Data (pp.173-194). London: Routledge, 1994

21. Braun V and Clarke V. Using thematic analysis in psychology. Qualitative Research in Psychology 2006; 3 (2): 77-101.

22. Löfstedt RE. Risk Management in Post-Trust Societies. London: Palgrave Macmillan, 2005.

23. Rimington J, McQuaid J and Trbojevic V. Application of risk based strategies to workers Health and Safety protection: UK Experience. The Ministry of Social Affairs and Employment (SZW), 2003.

24. Van Tol, J. Summary analysis of the risk-regulation reflex entrenched beliefs and six possible avenues for solutions. 'Veiligheid boven alles? Essays over oorzaken en gevolgen van de risicoregelreflex' [Safety above all? Essays on causes and effects of the risk-regulation reflex]. The Hague: Boom Lemma, 2011.

25. Petts J, Horlick-Jones T and Murdock G. Social amplification of risk: The media and the public. Health and Safety Executive. Norwich: The Stationery Office, 2001.

26. Boden D. Reinventing the global village: Communications and the revolutions of 1989. In AA Giddens (Ed.), Human Societies. Polity Press, Cambridge, 1992.

27. Löfstedt RE. The 'plateau-ing' of the European better regulation agenda: An analysis of activities carried out by the Barroso Commission. Journal of Risk Research 2007; 10 (4): $423-447$.

28. Slovic P. Perception of risk. Science 1987; 236: 280-285. 
29. Baggot R. Regulatory reform in Britain: The changing face of self-regulation. Public Administration 1989; 67: 435-454.

30. Dalton AJP. Lessons from the United Kingdom: Fightback on workplace hazards, 1979-1992. International Journal of Health Services 1992; 22 (3): 489-495.

31. European Commission (EC). Smart Regulation in the European Union. Communication from the Commission to the European Parliament, the Council, the European economic and social committee and the committee of the regions, 2010.

32. Hutter BM. The Attractions of Risk-based Regulation: Accounting for the emergence of risk ideas in regulation. London: London School of Economics and Political Science, 2005.

33. Hood C, Rothstein H and Baldwin R. The Government of Risk, Understanding Risk Regulation Schemes. Oxford: Oxford University Press, 2001.

34. Renda A. Impact Assessment in the EU: The state of the art and the art of the state. Centre for European Policy Studies, Brussels, 2006.

35. Torriti J. (Regulatory) impact assessment in the EU: A tool for better regulation, less regulation, or less bad regulation? Journal of Risk Research 2007; 10(2): 239-276.

36. Ackerman F and Heinzerling L. Priceless: On Knowing the Price of Everything and the Value of Nothing. New York: The New Press, 2004.

37. James $\mathrm{P}$, Tombs $\mathrm{S}$ and Whyte $\mathrm{D}$. The Löfstedt review of health and safety regulation: A critical evaluation. The Institute of Employment Rights, 2012.

38. Black C. Working for a Healthier Tomorrow. London: The Stationery Office, 2008.

39. Black C and Frost D. Health at Work: An independent review of sickness absence. The Department for Work and Pensions. London: The Stationery Office, 2011.

40. Harrison J. Occupational safety and health in the United Kingdom: Securing future workplace health and wellbeing. Industrial Health 2012; 50: 261-266. 
Table 1: Stakeholder groups represented and number of contributors in focus groups

\begin{tabular}{|c|c|}
\hline Stakeholder group & Number of contributors \\
\hline Government agencies & 7 \\
\hline Professional associations & 3 \\
\hline OSH practitioners & 2 \\
\hline Insurance associations & 2 \\
\hline Trade associations & 2 \\
\hline Employer association & 1 \\
\hline Trade unions &
\end{tabular}


Table 2: Findings - Stakeholder interviews (40 participants) and Stakeholder focus groups (18 participants)

\begin{tabular}{|c|c|c|}
\hline THEME & SUBTHEME & DESCRIPTOR \\
\hline \multirow[t]{2}{*}{$\begin{array}{l}\text { Reiterating } \\
\text { OSH legitimacy }\end{array}$} & Perception of $\mathrm{OSH}$ & $\begin{array}{l}\text { Public perception of } \mathrm{OSH} \text { and policy makers } \\
\text { The role of the media }\end{array}$ \\
\hline & Perception of $\mathrm{OSH}$ risk & $\begin{array}{l}\text { Perception and understanding of risk by stakeholders both within and } \\
\text { outside of the OSH system } \\
\text { Societal perception of risk in comparison to other types of risk } \\
\text { Understanding and perception of risk across countries and cultures } \\
\text { Positioning of OSH risk to business } \\
\text { Raising awareness and focussing on education activities, like } \\
\text { introducing risk education into schooling }\end{array}$ \\
\hline $\begin{array}{l}\text { Prioritising } \\
\text { health and well- } \\
\text { being in OSH }\end{array}$ & Health in $\mathrm{OSH}$ & $\begin{array}{l}\text { Historical focus of OSH on predominantly safety issues } \\
\text { Increasing confusion between health and wellbeing } \\
\text { Complexity/intangibility of health and inconsistencies in its } \\
\text { measurement } \\
\text { The need to move the onus/responsibility away from the individual } \\
\text { and towards the employer } \\
\text { Financial costs associated with occupational health and who pays }\end{array}$ \\
\hline \multirow[t]{4}{*}{$\begin{array}{l}\text { Genuine } \\
\text { evidence-based } \\
\text { policy making }\end{array}$} & $\begin{array}{l}\text { Political and economic } \\
\text { influences }\end{array}$ & $\begin{array}{l}\text { Economic climate influence } \\
\text { The effect of red-tape, administration and politics } \\
\text { EU influence } \\
\text { Deregulation }\end{array}$ \\
\hline & $\begin{array}{l}\text { Multi-policy } \\
\text { proportionate approach }\end{array}$ & $\begin{array}{l}\text { The potential of having a combination of policy initiatives to regulate } \\
\text { OSH in the future (both hard and soft law) } \\
\text { Consultation with stakeholders }\end{array}$ \\
\hline & $\begin{array}{l}\text { Long term, independent } \\
\text { thinking }\end{array}$ & $\begin{array}{l}\text { The need for thinking that is independent from political ideology and } \\
\text { is orientated towards long term benefits rather than short term } \\
\text { considerations }\end{array}$ \\
\hline & Measurement & $\begin{array}{l}\text { Demonstrating cause and effect of policy actions } \\
\text { Insufficient measurement timeframes }\end{array}$ \\
\hline \multirow[t]{3}{*}{$\begin{array}{l}\text { Promoting } \\
\text { leadership } \\
\text { and business } \\
\text { engagement } \\
\text { in OSH }\end{array}$} & Engaging business & $\begin{array}{l}\text { Understanding that business responds to legal, business/economic, } \\
\text { and ethical drivers } \\
\text { Engagement of organisations' leaders and managers } \\
\text { Integration of OSH into 'mainstream' management }\end{array}$ \\
\hline & $\begin{array}{l}\text { Educating business } \\
\text { leaders }\end{array}$ & $\begin{array}{l}\text { Educating the next generation of business leaders/managers on OSH } \\
\text { issues }\end{array}$ \\
\hline & The OSH 'industry' & $\begin{array}{l}\text { OSH industry becoming a silo inhibiting its integration into } \\
\text { mainstream business practice }\end{array}$ \\
\hline
\end{tabular}




\begin{tabular}{|l|l|l|}
\hline $\begin{array}{l}\text { Strengthening } \\
\text { stakeholder } \\
\text { partnership }\end{array}$ & $\begin{array}{l}\text { Stakeholder/practitioner } \\
\text { autonomy and influence }\end{array}$ & $\begin{array}{l}\text { Constraints by policy changes (at stakeholder level) } \\
\text { The remit practitioners are given and business response }\end{array}$ \\
\hline & Working in partnership & $\begin{array}{l}\text { The need for closer inter-dependent working within government; } \\
\text { between non-governmental stakeholders; and between government } \\
\text { and non-governmental stakeholders }\end{array}$ \\
\hline
\end{tabular}

